\title{
Masters-level education in archaeoastronomy at the University of Wales Trinity Saint David
}

\author{
Nicholas Campion $^{1}$ and J. McKim Malville ${ }^{2}$ \\ ${ }^{1}$ Sophia Centre for the Study of Cosmology in Culture, \\ School of Archaeology, History and Anthropology, \\ University of Wales Trinity Saint David, \\ Lampeter, Ceredigion, Wales, SA48 7ED, UK \\ email: ncampion@tsd.ac.uk \\ ${ }^{2}$ Department of Astrophysical and Planetary Sciences, \\ University of Colorado, Boulder, Colorado 80309, USA \\ email: kim.malville@colorado.edu
}

\begin{abstract}
The class in Archaeoastronomy at the University of Wales Trinity Saint David is taught as part of the MA in Cultural Astronomy and Astrology, within the University's School of Archaeology, History and Anthropology. This paper will present and review some of the postgraduate work produced in the course, reporting on its findings as examples of the level of work that may be expected on a taught MA course at a UK University.
\end{abstract}

Keywords. archaeoastronomy, University of Wales

\section{Introduction}

The MA in Cultural Astronomy and Astrology (MA CAA) at the University of Wales Trinity Saint David is in its ninth year of teaching, and fourth year at the University of Wales (it was taught in the Department of History at Bath Spa University from 2002 to 2007-8). The MA syllabus contains an emphasis on the religious aspects of the human relationship with the sky, and its methodologies tend to be a combination of the historical and anthropological (Campion 2008; Campion \& Holbrook 2008). The Archaeoastronomy module was launched in January 2010, with Malville as the lead tutor. Students take two compulsory modules and then choose four others, from a list which includes Archaeoastronomy. They then write a 20,000-word dissertation based on an independent research project.

The emphasis in the archaeoastronomy module is on the astronomical component of archaeoastronomical methodology as it was felt that, in a single 20-credit module, requiring only 200 hours of formal study, it was inappropriate to include archaeology. Students can take several pathways through the module assessment: they may take a literary approach (for example, examining the history of the discipline) an ethnographic one (for example, investigating the modern use of archaeoastronomical sites by tourists or pagans), or astronomical (for example, conducting site surveys in order to test for possible astronomical alignments). The technical level at which we expect research to be conducted is determined by the fact that this is a distance-learning course and students need have no prior experience: this is their introduction to practical archaeoastronomy and it is seen as a training exercise. Research that contributes to the wider discipline is not required, although it is expected it may occur in the best student work. Also, at this level, we expect students to work with GPS, tape and compass. Theodolites were 
available through the School of Archaeology, although we announced that they were optional field techniques.

The astronomical option proved popular and, when the module was launched in the academic year 2009-10, seven out of nine students in the initial cohort set out to conduct site surveys in order to satisfy the requirement of a term paper. We saw these surveys as positive alternatives to library research. We report on three of the student projects as examples of the only current attempt, of which we know, to create an academic programme in archaeoastronomy.

\section{Three student projects}

\subsection{Fabio Silva, 'Orientation of Neolithic tombs in central Portugal'}

Fabio Silva re-examined the comprehensive survey of the orientations of Iberian Neolithic dolmens carried out by Hoskin (Hoskin \& Pérez 1998; Hoskin 2001) and colleagues, including measurements of the axial orientation of some examples in central Portugal. Hoskin's study has already led to further work, for example by Gil-Merino et al. (2009). Hoskin concluded that most tombs in the Mondego plateau were aligned towards sunrise during the winter seasons, whereas tombs in the Vouga, Paiva and other nearby river basins were aligned towards winter 'sunrise/sun-climbing' (sun-climbing being alignments to the sun as it climbs out of the horizon after the actual sunrise). He then advanced the possibility that the dolmens themselves were aligned to sunrise on the day they were built (in winter), which would account for the spread in azimuths.

Archaeological evidence (Senna-Martinez \& Ventura 2008) suggested that the megalith builders' way of life as semi-nomad pastoralists was tied to the orientation of the dolmens, namely that the monuments were built during the winter seasons when the pastoralists would be in lower ground, which is where we find the tombs in the Mondego basin. However, not all measured dolmens fit this picture, and especially not the ones from nearby basins. To test this seasonal model a new survey was planned and conducted during the spring of 2010, which incorporated previously unmeasured tombs from the region as well as trying to take note of landscape features and other possible orientations. Further data is given in Silva (2010).

In total, Silva measured the axial orientation of 31 dolmens, using a magnetic compass as, given the nature and state of the monuments, the precision of a theodolite would not translate into significantly greater orientation precision. Care was taken to avoid magnetic anomaly issues, and a new technique for obtaining the local values for the magnetic deviation was developed (Fig. 1). This involved choosing a number of features in the landscape surrounding each tomb, taking their azimuth bearings from the tomb, then going to each of them, recording their GPS positions and azimuth bearing of the tomb. Later, the compass bearings can be compared with the ones extracted from the GPS data. Their difference gives the magnetic declination, which one can average over all the measured features and get a standard deviation. This technique proved to be quite reliable for four to six measured features, giving average values close to the NOAA estimates and with standard deviations of roughly half a degree.

Silva's survey confirmed most of the results of the previous survey by Hoskin and colleagues, confirming Hoskin's measurements to within $3^{\circ}$ in declination. However, he also opened up possible avenues of interpretation and further research, finding that more than half of the tombs of the region did not match the winter sunrise/sun-climbing interpretation as they had positive declinations, and thus would indicate spring or summer solar alignments. Also there were a few outliers, i.e. tombs that didn't fit this picture. 


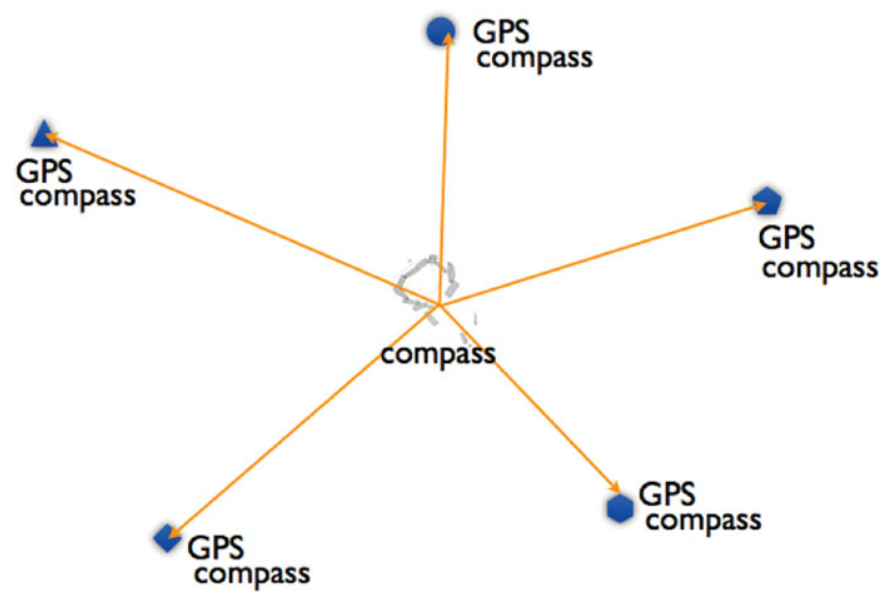

Figure 1. Obtaining local values for the magnetic deviation.

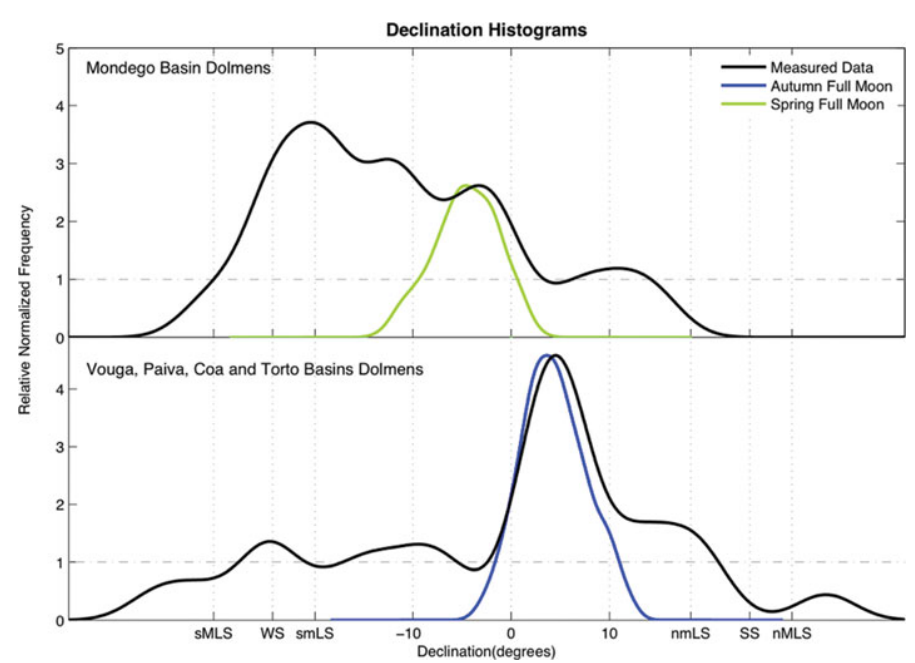

Figure 2. Histogram illustrating orientation of dolmens to spring and autumn Full Moons.

Some of the surveyed tombs suggest non-solar alignments, possibly lunar or even stellar (the entrances of a couple of Mondego dolmens forming one of the oldest Neolithic necropoleis of the region face towards the northern sky, which might indicate an early stellar association with death and the afterlife). The Mondego plateau dolmen declination histogram exhibits a peak at the expected position of the Spring Full Moon peak, whereas dolmens in other nearby basins have their most significant peak at the expected Autumn Full Moon peak (Fig. 2). These Equinoctial Full Moons are the closest Full Moons to the equinox, defining a point in space (i.e. in the horizon) as well as in time, in which the moonrise and sunrise points cross over. Essentially, the highest peaks in the declination histogram closely match the expected (simulated) Spring Full Moon and Autumn Full Moon rises, and also the minor standstills, which indicates a predominance of alignments to the Moon at various points (equinoctial and solstitial) of its yearly cycle, which would explain every single one of the dolmens measured by Silva. A fascinating outcome of his investigations has been the displacement of equinoctial full moons from the day of equinox, late in the spring and early in the fall, mimicking the effect of half-day counts. 
2.2. Tore Lomsdalen, 'Astronomy and intentionality in the temples of Mnajdra'

Lomsdalen examined the Neolithic Mnajdra South Temple on Malta, one of the survivors of the enigmatic temple-building culture on Malta (Trump 2002). It has already been suggested that the temples may have been constructed with intentional astronomical alignments, including possibly to the heliacal rising of the Pleiades and lunar standstills (Ventura 1999; Cox 2001, 2009). Ventura (1999) found that Maltese shaft tombs have a tendency to a south-easterly orientation. Of the extant Neolithic megalithic monuments in Malta, the Mnajdra South Temple is the only one with a seemingly intentionally defined eastern orientation. From the temple site, the horizon has an elevation about $4^{\circ}$ at equinox and summer solstice and close to $0^{\circ}$ at winter solstice. Lomsdalen's study investigated solar alignments at the spring equinox and the summer and winter solstices. Further data on this study is included in Cox \& Lomsdalen (2010). Lomsdalen's project (which is ongoing) requires photographing and documentation of actual solar and lunar risings in order to confirm or disconfirm the evidence of site plans.

At present the architecture of Mnajdra South Temple allows a cross-jamb view of sunrise around the time of the solstices. The entrance to the temple is formed by opposed pairs of orthostats, forming a corridor about $3 \mathrm{~m}$ long, $1.75 \mathrm{~m}$ wide and $3.1 \mathrm{~m}$ high. Two diagonal views seen from the waist of the temple, lightening the rearmost inside corner of a southern and northern erected orthostat, indicate respectively the sunrise at summer and winter solstice, based on an offset-illumination (Fig. 3).

A deliberate orientation could have been found by bisecting the position of the sightlines of the winter and summer sunrise. However, in the period around $3000 \mathrm{BC}$, the same view would have coincided with the rising point of the Pleiades close to the time of the spring equinox. Fig. 4(a) illustrates the sunrise at spring equinox 2010 illuminating the central altar situated $15.4 \mathrm{~m}$ back from the entrance. Fig. $4(b)$ illustrates sunrise at the summer solstice 2010 seen from the entrance illuminating the southern orthostat. So far, Lomsdalen's photographic documentation confirms Mandjra's orientation to the spring equinox, and summer and winter solstice, rising sun.

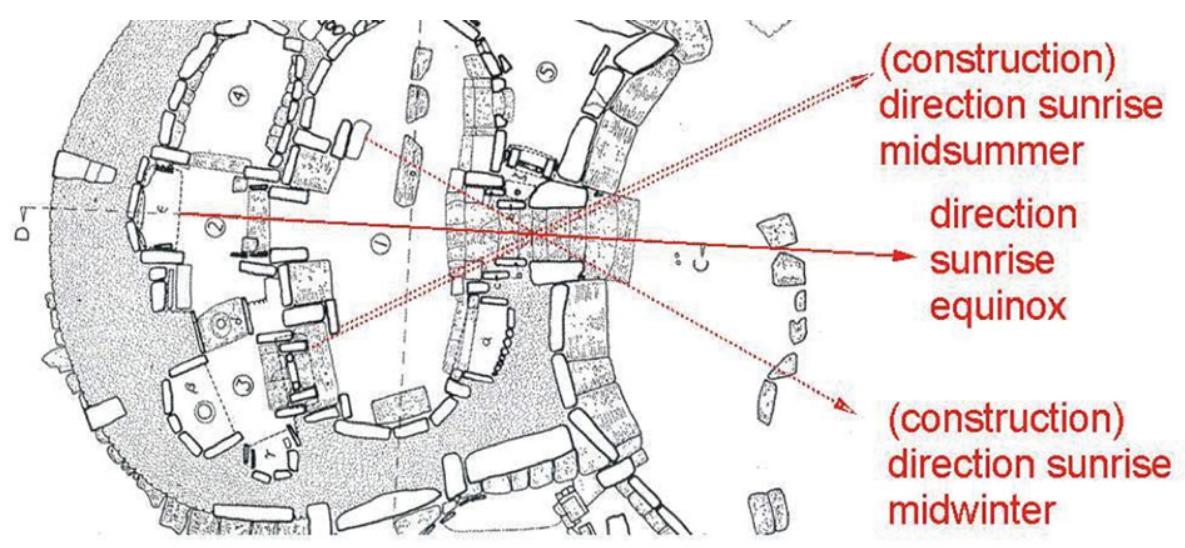

\title{
Orientation of Mnajdra South Temple to sunrise at the equinox; cross-jamb views to the solstices
}

\author{
Temple Plan from JD Evans 1971 \\ by courtesy Continuum Publishing \\ copyright $₫ 2010$ Continuum Publishing
}

Figure 3. Solar orientation at equinox and solstices at the Mnajdra South Temple. (Adapted from Evans 1971) 

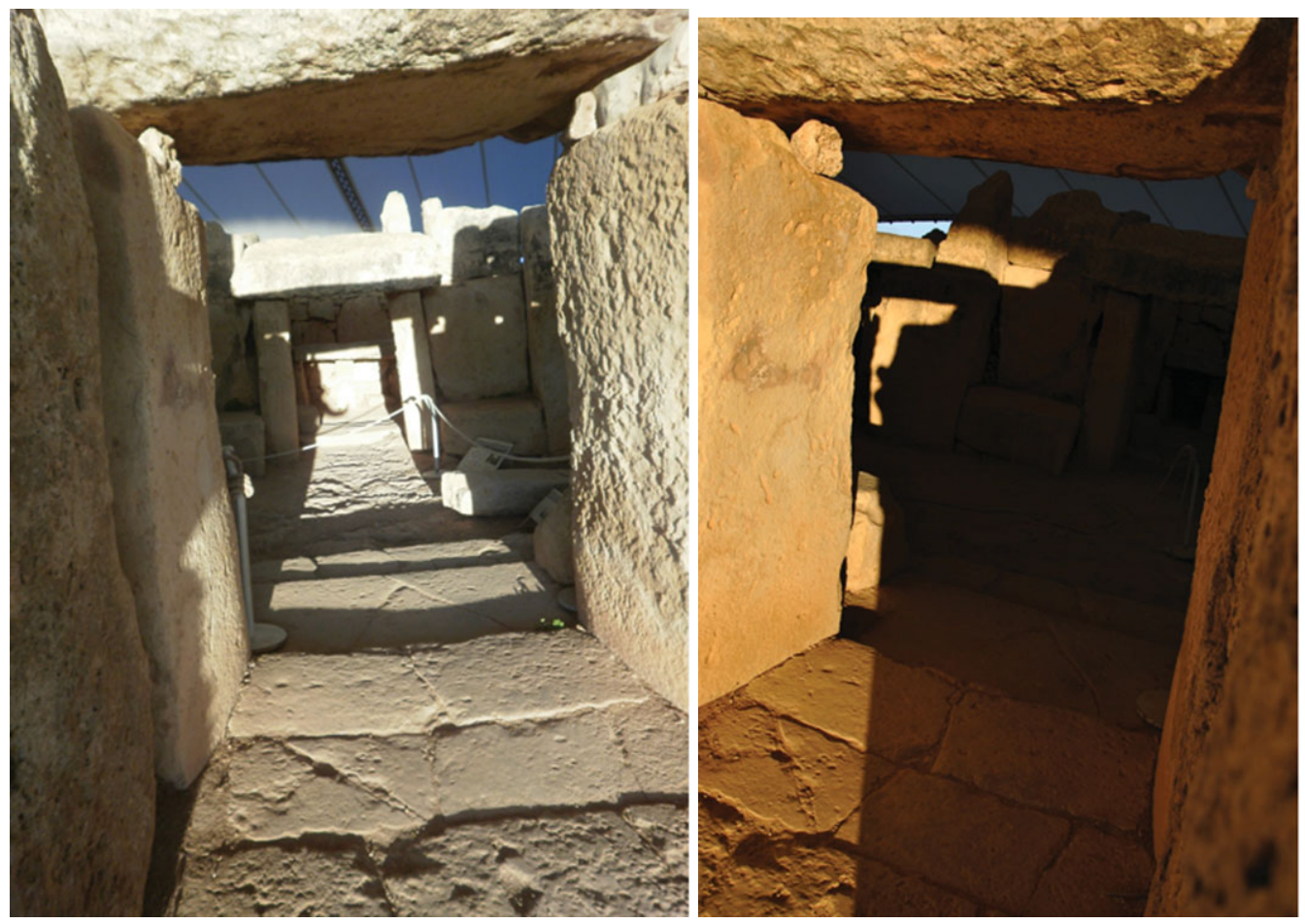

Figure 4. (a) (left): Spring equinox sunrise at Mnadjra illuminating the central altar situated $15.4 \mathrm{~m}$ back from the entrance. $(b)$ (right): Summer solstice sunrise at Mnadjra seen from the entrance illuminating the southern orthostat.

\subsection{Liz Henty, 'Recumbent Stone Circles: review of archaeoastronomical theory based on fieldwork conducted at three sites'}

Henty's project reviewed archaeoastronomical theory pertaining to the megalithic recumbent stone circles (RSCs) of northeast Scotland. It included a detailed study of three such circles (Sunhoney, Midmar Kirk and Tomnagorn) within a close area west of Aberdeen. Previous published research into RSCs includes that by Thom (1967), Ruggles \& Burl (1985) and Burl (2000). Ruggles (1999: 97-99) includes an extensive literature review, suggesting that both landscape features (orientation upon prominent landmarks) and astronomical factors (possible alignment to midsummer full moon) were significant. Burl (1969-70: 75) suggested a NE alignment to midsummer sunrise. Henty was interested in both celestial and topographical considerations. She conducted her own survey using compass and GPS and concluded that there are possible discrepancies in Thom's plans, suggesting the need for fresh surveys. (Thom's plans are all based on a 'best-fit' circle. If lines are drawn that link the stones, they all appear to be flattened circles). Henty also considered the midsummer Full Moon hypothesis. Using Stellarium planetarium software, she found that, at the sites' latitude, in midsummer the time between the moon's rising and setting is around four hours. It skims along the horizon (Fig. 5) and because the horizon altitude behind the recumbent is around $8^{\circ}$ at both Midmar Kirk and Sunhoney, it cannot be visible (using a test date of 11 June 2006, full moon at major southern standstill) $\dagger$

$\dagger$ This is evident in the published literature, e.g. Ruggles, Archaeoastronomy no. 6 (suppl. to Journal for the History of Astronomy 15), 1984, S74-S75. -Ed. 


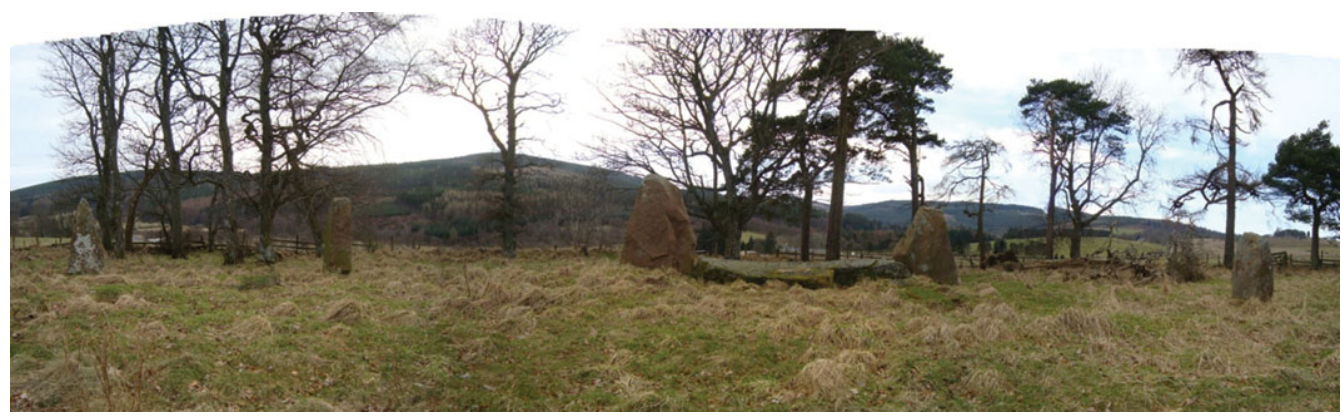

Figure 5. The distant horizon from the Sunhoney circle.

Figure 6. Tomnagorn: Bennachie in the distance and megalith in the foreground. The recumbent was behind Henty.

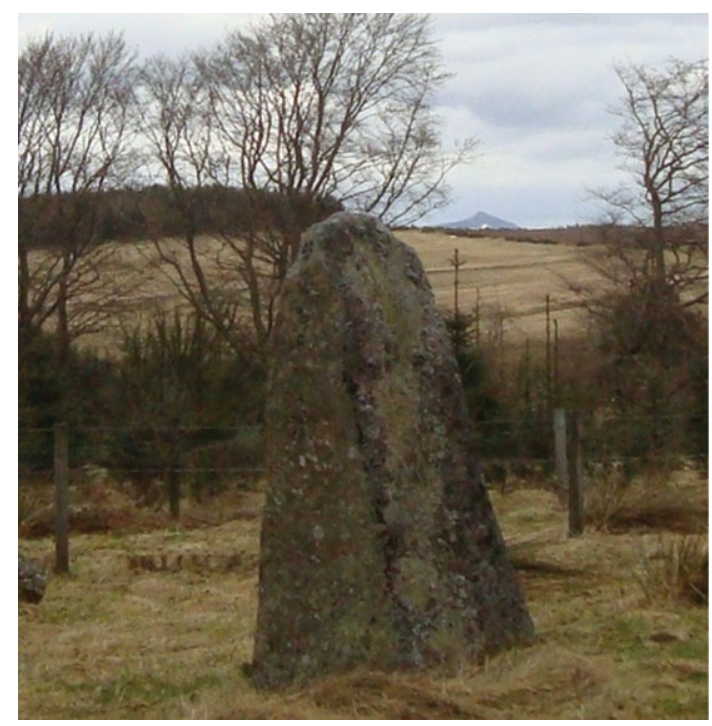

Indeed, the visible winter solstice sunset occurs some $26^{\circ}$ south of the recumbent centre. Further research needs to be carried out to find where in the circle the astronomical events are actually visible both at midsummer and midwinter. Focusing, following Ruggles (1999: 97-99), on topographical features, Henty found alignments, not previously identified, to landscape features opposite the recumbent. At Tomnagorn, for example, the recumbent is opposite Bennachie, a locally revered landscape feature (Fig. 6). At Sunhoney and Midmar Kirk the recumbent is opposite the Barmekin of Echt, an ancient cattlefold, which brings to mind Sims' (2006) theory that the monuments were built by cattle herders, given the dating problems in relating the cattle-fold to the megalithic circle.

\section{Conclusion}

The function of the MA CAA archaeoastronomy module is to train students who may have no prior experience in the basic tools of archaeoastronomy and familiarise them with the literature. At this stage of a taught MA, they are not expected to conduct original research. They are, however, expected to use their initiative in designing a suitable project, making contact with other researchers, and exploring appropriate resources. In this sense, students are expected to be able to function as autonomous learners. All students encountered a range of problems, from time limits to site access and poor weather, and part of the training is a test of their ability to navigate such difficulties and cope with problems of uncertain evidence. Such pedagogical issues could be discussed within the 
European Society for Astronomy in Culture (SEAC) Education Committee. The three students whose work is reported on here showed great initiative in the design and conduct of their projects and have produced results which add to prior studies. We regard this as a good foundation for further work.

\section{References}

Burl, A. 1969-70, The Recumbent Stone Circles of north-east Scotland. Proceedings of the Society of Antiquaries of Scotland 102, 56-81.

Burl, A. 2000, The Stone Circles of Britain, Ireland and Brittany, Yale University Press, New Haven \& London.

Campion, N. 2008, Teaching cultural astronomy: on the development and evolution of the syllabus at Bath Spa University and the University of Wales, Lampeter. In J. Holbrook, R. T. Medupe \& J. Urama (eds), African Cultural Astronomy: Current Archaoeastronomy and Ethnoastronomy Research in Africa, Astrophysics and Space Science Proceedings, Springer Verlag, Amsterdam, pp. 109-119.

Campion, N. \& Holbrook, J. 2008, Cultural astronomy: a conversation about degree programs and research questions from both sides of the Pond. Innovations in Teaching Major \& Graduate Students Series, Spark: The American Astronomical Society Education Newsletter, 9-11.

Cox, J. 2001, The orientations of prehistoric temples in Malta and Gozo. Archaeoastronomy: the Journal of Astronomy in Culture 16, 24-37.

Cox, J. 2009. Observations of far-southerly moonrise from Hagar Qim, Ta'Hagrat, and Ggantija temples from May 2005 to June 2007. In J. A. Rubiño-Martín, J. A. Belmonte, F. Prada \& A. Alberdi (eds), Cosmologies across Cultures, Astronomical Society of the Pacific, Prvo, Utah, pp. 344-349.

Cox, J. \& Lomsdalen, T. 2010, Prehistoric cosmology: observations of moonrise and sunrise from ancient temples in Malta and Gozo. Journal of Cosmology 9, 2217-2231.

Evans, J. D. 1971, The Prehistoric Antiquities of the Maltese Islands: a Survey, Athlone Press, London.

Gil-Merino, R., Moreno Gallo, M. A., Delibes de Castro, G. \& Gonzáles-Garcia, A. C. 2009, Interdisciplinary approach to megalithic tombs in northern Iberia. In J. A. Rubiño-Martín, J.A. Belmonte, F. Prada \& A. Alberdi (eds), Cosmologies across Cultures, Astronomical Society of the Pacific, Prvo, Utah, pp. 349-353.

Hoskin, M. \& Pérez, T. P. 1998, Studies in Iberian archaeoastronomy: (5) orientations of megalithic tombs of northern and western Iberia. Archaeoastronomy no. 23 (suppl. to Journal for the History of Astronomy 29), S63-79.

Hoskin, M. 2001, Tombs, Temples and their Orientations, Ocarina Books, Bognor Regis.

Ruggles, C. L. N. 1999, Astronomy in Prehistoric Britain and Ireland, Yale University Press, New Haven \& London.

Ruggles, C. L. N. \& Burl, A. 1985, A new study of the Aberdeenshire Recumbent Stone Circles, 2: interpretation. Archaeoastronomy no. 8 (suppl. to Journal for the History of Astronomy 16), S25-60.

Senna-Martinez, J. C. \& Ventura, J. 2008, Do mundo das sombras ao mundo dos vivos: Octávio da Veiga Ferreira e o megalitismo da Beira Alta, meio século depois. In Homenagem a Octávio da Veiga Ferreira-Estudos Arqueológicos de Oeiras 16, Câmara Municipal, Oeiras, pp. $317-350$.

Silva, F. 2010, Cosmology and the Neolithic. A new survey of Neolithic dolmens in central Portugal. Journal of Cosmology 9, 2194-2206.

Sims, L. 2006, Lighting up Dark Moon: ethnographic templates for testing paired alignments on the Sun and the Moon. http://homepages.uel.ac.uk/ L.D.Sims/Lighting\%20Up\%20Dark\%20Moon.pdf .

Thom, A. 1967, Megalithic Sites in Britain, Oxford University Press, Oxford.

Trump, D. 2002, Malta Prehistory and Temples, Midsea Books, Malta.

Ventura, F. 1999, Evaluating the Evidence for Interest in Astronomy in the Temple Period of Malta (3600-2500 BCE). Paper delivered at the second conference on the Inspiration of Astronomical Phenomena (INSAP II), Malta, January 1999. 